\title{
Afinal, o Que é Cidadania?
}

\author{
After all, What is Citizenship?
}

Eis uma pergunta que parece impertinente, porque "cidadania" significaria alguma coisa de conhecimento geral. Seria esse um fato? Cidadania tem sido uma palavra muito usada em discursos, pois cria uma imagem positiva. Ao mesmo tempo, os discursos cada vez mais têm sido usados para cativar pessoas sem, entretanto, se tornarem ações e já esse fato seria uma questão de falta de cidadania.

Diria que cidadania poderia ser resumida em se ter uma atitude ética, e ética não é nada mais do que respeitar ao próximo, independentemente de sexo, etnia, crença religiosa ou filosófica e também de espécie. Vale lembrar que liberdade está intrinsecamente vinculada à cidadania e ao respeito ao outro e que, portanto, está absolutamente limitada pela liberdade do outro.

É fato que na época atual, como sempre, a ética tem tido interpretações variadas, feitas em acordo com momentos político-sociais e com as diferentes áreas de atividade. Não vou comentar as questões de cidadania nas culturas ancestrais e nem as discussões sobre ética que existem desde então. Vale lembrar que sempre essas questões têm envolvido características das épocas e políticas vigentes e, principalmente, as questões dos diferentes grupos sociais, que existem até hoje no mundo inteiro, muito embora só na Índia se reconheça o fato e os rotule como "castas".

Aparentemente tanto ética quanto cidadania têm tido interpretações variadas, com os diferentes grupos, ou castas, tendo seu próprio conceito a respeito, e com isso criando conflito social que, graças aos diferentes meios de comunicação, é crescente pelo mundo afora.

No Brasil a questão é gritante. Cidadania parece ser algo inexistente. Todos parecem referir cidadania como algo importante, que deve existir, e citá-la faz sucesso nos discursos dos interessados em ter popularidade. Ao mesmo tempo a grande maioria pretende ser cidadã e que maus cidadãos são os outros e principalmente os políticos que elegeram, por ter com eles algum tipo de afinidade.

Atualmente vivemos algum tipo de crise que é discutível quanto a sua origem,
Diana Helena de

Benedetto Pozzi

Universidade de São Paulo. Faculdade de Medicina, São Paulo, Brasil 
se seria política ou econômica, e que está repercutindo fortemente na economia e, principalmente, na vida de todos os brasileiros e tendo até, graças à globalização, repercussão significativa no exterior. Mesmo que se pretenda que a crise tenha uma origem politica ou econômica, ambos os aspectos têm basicamente como origem a cidadania da população em geral.

Pensando nas diferenças existentes entre as populações que habitam a América, lembramos que suas regiões foram colonizadas na mesma época por pessoas de diferentes procedências, mas que tinham a mesma situação social em seus países de origem. Foram eles que conquistaram os territórios e nele se estabeleceram. Entretanto, a evolução do processo foi bastante distinta, muito embora tivesse em comum receberem imigrantes de diferentes procedências e terem adquirido mão de obra barata, escravos, para trabalhar no campo e na atividade doméstica.

Quando observamos o povo do hemisfério norte, percebemos uma população orgulhosa de seu país e que entende que "a grama do vizinho não é mais verde", muito embora possa ser em alguns aspectos. Entretanto, desde o berço, no Brasil aprendemos que a grama do vizinho "é mais verde". Resulta aquilo que no século passado, nos anos 6o, chamávamos de evasão de divisas, pois gostamos de comprar no exterior ou produtos aqui montados por empresas estrangeiras, com a consequente remessa de lucros. Também ocorre de exportarmos matéria prima que será manufaturada no exterior para ser adquirida com o "selo de qualidade" externo. Seguramente isso se reflete na economia. É fato que atualmente vivemos no mundo globalizado, o que poderia explicar a situação ao menos parcialmente. Entretanto, leva à pergunta: devemos ser tão somente exportadores de matérias-primas e "mão de obra barata" para empresas estrangeiras que recebem bons dividendos por sua produção industrial exportável e com isso até resolvem suas crises?

Se for falar em corrupção, outra falha grave na cidadania: só nos preocupamos com a corrupção grosseira que ultimamente tem ocupado diariamente os noticiários e que envolve algumas grandes empresas e políticos. E a corrupção que ocorre no dia a dia, à qual já estamos acostumados e nem mais rotulamos como corrupção? Afinal para existir corrupção precisam existir duas partes, a que compra (corrompe) e a que é comprada (corrompida) e, se isso ocorre nos grandes atos de corrupção, também ocorre nos pequenos. Continuamente se paga para alguém com o objetivo de se receber alguma vantagem como no caso das multas dos mais variados tipos. Seria infindável a lista de "pequenas coisas" que se faz com o intuito de "levar vantagem" dentro do "jeitinho brasileiro", e que parece ser uma atitude normal, que já estaria incorporada como parte de nossa cultura e tem sido associada à ideia de que "é dando que se recebe".

Talvez se pense que cidadania só esteja vinculada à questão de Estado e, aparentemente, a maioria entende que: Estado é uma entidade que tem deveres para com os cidadãos. Talvez alguns pretendam que o Estado seja "uma enorme granja de galinhas poedeiras de ovos de ouro". A ideia de que o Estado somos todos nós, que vivemos na sociedade e devemos contribuir para sua manutenção parece não predominar. A obrigação do cidadão estaria resumida a eleger pessoas que devem cuidar das coisas da entidade Estado e dar benefícios para a população. Ora, como o Estado poderá cuidar 
de seus cidadãos se estes não contribuírem? E como cidadãos podem exigir do Estado se não contribuem adequadamente com ele e pretendem receber só os benefícios?

Os cidadãos devem contribuir com o Estado e exigir que este lhes retribua com os benefícios fundamentais para toda a comunidade e também para seu desenvolvimento. O Estado recebendo essa contribuição, que não é estrita a impostos, deverá dar a todos os seus cidadãos boas condições de vida, com boa saúde e uma educação que lhes permita uma atividade que propicie um aprimoramento do Estado. Ele deve inclusive desenvolver os meios que permitam aos cidadãos incrementar os recursos do Estado, para um melhor atendimento de toda a sociedade que o constitui. Dessa maneira, muito provavelmente, as pessoas terão não só um sentimento de orgulho pessoal, mas também de pertencer à sociedade e sentirem-se cidadãs. Notoriamente pessoas são diferentes e tem habilidades diversas e, felizmente, é o conjunto dessas habilidades que permite uma sociedade pujante por ser criativa. Ao mesmo tempo todas as pessoas têm basicamente as mesmas necessidades que devem ser atendidas com qualidade, de tal maneira que elas possam se sentir cidadãs.

Lamentavelmente não é isso que temos visto acontecer. A própria população tem aprendido que não é importante uma boa formação de pessoas, o que tem interessado é simplesmente uma diplomação que lhe trará alguma vantagem pecuniária. Aparentemente não interessa ser cidadão, mas tão somente ter poder aquisitivo para se equiparar aos demais. Quando ocorre uma crise, o que é cortado de maneira significativa é o investimento em Educação e no Sistema de Saúde, que deve ser próprio para atender à saúde e não só à doença. Aparentemente essa conduta, que tem sido admitida como adequada, tem sido justificada pela necessidade de consumir, a importância de ter e não a de ser, pois isso seria interessante para a economia.

Piketty, em seu livro $O$ capital no século XXI [2], no qual ele escreve sobre sua preocupação, que é o crescimento da desigualdade no mundo, relata que a possibilidade de uma mudança seria dependente de uma mudança nos usos e costumes e, principalmente, de uma melhor educação, com a formação e capacitação das pessoas a fim de que elas possam ser saudáveis e ter uma maior e melhor participação na sociedade, exercendo suas competências, sentindo auto respeito e sendo cidadãs. Pelo seu livro fica aparente que o futuro será problemático se isso não ocorrer. Anthony Giddens, em seu livro Runaway world [1], também escreve sugerindo a urgência de mudanças do comportamento das pessoas, pois caso contrário iremos ter não uma aldeia global, mas uma pilhagem global.

Quando a urgência em ter predomina, e a cidadania não está presente, surgem os maiores problemas. A urgência no ter, criada pela necessidade de consumo para "melhorar a economia”, tem obtido resultados discutíveis e provavelmente só está aumentando rapidamente a desigualdade e criando para muitos a necessidade de ter coisas por qualquer meio, inclusive pela violência, não só física como a mental e sem se ater a uma postura ética.

Observando os fatos que ocorrem com esse tipo de procedimento fica a impressão de que atualmente existe a predominância do materialismo capitalista selvagem, consumista, incentivado pela propaganda que promove as modas que convidam as pessoas a ter e a se comparar e assim deixar de ser para tão somente parecer. Os meios 
de informação, principalmente a internet, têm sido utilizados predominantemente com esse objetivo. Isso é feito de tal maneira que atualmente, na procura da "grama mais verde”, existem as grandes migrações e até já está em andamento um significativo comércio nessa área para levar pessoas que vivem em locais em litígio, que querem se mudar e estão interessados primordialmente nos "países ricos".

Aparentemente a ética e a cidadania estão esquecidas, são figuras de retórica. Existem os vários códigos de ética e a cidadania parece só se manifestar em situações pontuais como limpeza da cidade, ecologia, celebrações públicas, liberdade sexual, entre outras que seriam "politicamente corretas" e tornam-se moda.

Cidadania seria seguir modas para poder pertencer a grupos? Cidadania não envolveria pensar e ter espírito crítico que permite avaliar os acontecimentos, inclusive as modas e as necessidades de consumo? Cidadania não implicaria em perceber a disparidade social crescente e suas consequências na violência? Cidadania não seria perceber e procurar sanar todos os tipos de violência que ocorrem e que não estão estritos à violência física? Cidadania seria se avocar direitos sem se lembrar dos deveres a eles associados? Ou seria pretender ter direitos adquiridos, se acomodar e nada fazer para continuar a merecê-los? Cidadania não seria criar condições para o outro ser e, consequentemente adquirir a possiblidade de ter? Cidadania seria procurar levar vantagem, e os outros que de danem? Ou seria tão somente ter a possibilidade de consumir e, assim, fazer a felicidade do mercado? Cidadania seria ensinar e formar cidadãos ou tão somente induzi-los a consumir? Cidadania seria cuidar do próprio gramado ou só invejar o do vizinho e até querer de qualquer modo se mudar e aproveitar a vantagem? Cidadania não seria respeitar o próximo, cada um com sua competência? Cidadania seria utilizar qualquer meio, explorando os mais diferentes seres a fim de ter lucro?

A diversidade quanto ao que seja cidadania tem levado aos mais diversos comportamentos e a uma vida bastante complicada. Tem sido dada ênfase à questão econômica como a causadora da questão social e as ações têm sido praticadas tendo como objetivo estrito a economia, que alguns pretendem que seria a solução dos problemas. Entretanto, como escreve Giddens [1], essas medidas têm significativamente alimentado o problema social. É crescente o número de pessoas que estão percebendo e se preocupando com a situação e Piketty [2] refere à necessidade de mudanças na sociedade para solucionar os problemas, pois a economia não deveria estar restrita a exercícios matemáticos sofisticados, ela é algo mais amplo, é uma questão também ligada à sociologia.

A observação do que acontece no Brasil e no mundo sugere fortemente que o problema básico no Brasil e no mundo é a cidadania, o comportamento das pessoas que constituem os estados. Essas pessoas, inclusive, são as responsáveis pela escolha de seus representantes que devem cuidar da melhor maneira do Estado, isto é, da população. É esse conjunto que irá produzir uma condição social e econômica para toda a sociedade, na qual as diferenças sejam respeitadas e as desigualdades minimizadas.

Aparentemente, cidadania é o que está faltando no mundo e, particularmente, no Brasil, para que a vida de todos possa ser melhor. 
REFERÊNCIAS

[1] GIDDENS, A. Runaway world - How globalization is reshaping our lives. London: Profile Books, 1999.

[2] PIKETTY, T. O capital no século XXI. Rio de Janeiro: Editora Intrínseca Ltda., 2014.

DiAnA helena de benedetto pozzI professora associada da Faculdade de Medicina da Universidade de São Paulo (FM-USP) e editora responsável da Revista de Cultura e Extensão USP - e-mail: revistacultext@usp.br 